\title{
Empréstimo Digital Controlado e direitos autorais no Brasil: algumas reflexões iniciais
}

\author{
Controlled Digital Lending and copyright in Brazil: some initial \\ considerations
}

\author{
Walter Eler do Couto ${ }^{\mathrm{a}, *}$ \\ Sueli Mara Soares Pinto Ferreira ${ }^{a}$ (D)
}

\begin{abstract}
RESUMO: Durante a pandemia de COVID-19, antigos problemas relacionados à harmonização entre os direitos autorais e os direitos culturais se intensificaram no Brasil, gerando dúvidas e debates entre profissionais da educação e da informação. Pela necessidade de isolamento social, as atividades culturais, educacionais e científicas passaram a ser exercidas a distância, dependendo muito das tecnologias digitais. Do ponto de vista tecnológico, as instituições estavam relativamente preparadas para esse desafio, mas a falta de políticas públicas mais claras a respeito do acesso à informação e à cultura gerou alguns efeitos paralisantes. Diante desse cenário, realizamos uma análise da resposta que bibliotecas estrangeiras deram ao problema, comparando legislações de direitos autorais distintas. Um dos conceitos que mais chamaram a atenção foi o de Empréstimo Digital Controlado, proposto há poucos anos pelas bibliotecas americanas, que facilitou o acesso remoto no contexto de isolamento social. O objetivo deste trabalho é analisar esse conceito para entender se ele poderia ser aplicado em outros países, como a França e o Brasil. Embora o Brasil não tenha limitações aos direitos autorais em benefício das bibliotecas, historicamente esse setor desempenha suas atividades com base em interpretações sistemáticas dos direitos culturais, que limitam extrinsecamente os direitos autorais. Dado esse fato, procuramos analisar se essa modalidade inovadora de empréstimo seria autorizada no Brasil com base nessa mesma interpretação sistemática, que envolve a função social dos direitos autorais e os direitos culturais no Brasil. Concluímos que o conceito é tão aplicável no Brasil quanto a digitalização para fins de preservação e o empréstimo tradicional, cabendo às instituições a responsabilidade de sua implementação.
\end{abstract}

Palavras-chave: Empréstimo Digital Controlado; Bibliotecas Digitais; Limitações aos Direitos Autorais; Direitos dos Usuários; Direitos Culturais.

ABSTRACT: During the COVID-19 pandemic, ancient problems related to the harmonisation between copyrights and cultural rights have intensified in Brazil, giving rise to doubts and debates between professors and information professionals. Due to the need of social distancing, cultural, educational and scientific activities started to be carried out remotely, in dependence of digital technologies. From a technological standpoint, the institutions were relatively prepared for this challenge, but the lack of direct policies concerning information and culture access gave rise to some paralyzing effects. In view of this scenario, we effected an analysis of the responses given by foreing libraries to problem, comparing distinct copyright laws. One of the concepts that stood out more was Controlled Digital Lending, proposed a few years ago by American libraries, which facilitated remote access in the context of social distancing. The aim of this work is to analyse this concept in order to understand if it could be applied in other countries, such as France and Brazil. Although Brazil does not have copyright limitations for libraries, this sector historically exerts its activities based in systematic interpretations of culture rights, that extrinsically limitate copyrights. Given this fact, we endeavour to analyse if this innovative modality of loan would be authorized in Brazil based on this same systematic interpretation, which involves the social function of copyrights and culture rights in Brazil. We conclude that the concept is as applicable in Brazil as digitization for preservation purposes and the traditional loan, with the institutions being responsible for its implementation.

Keywords: Controlled Digital Lending; Digital Libraries; Limitations and exceptions to copyright; Copyright Users' Rights; Cultural Rights.

\footnotetext{
a Programa de Pós-Graduação em Ciência da Informação, Escola de Comunicações e Artes, Universidade de São Paulo, São Paulo, SP, Brasil.

*Correpondência para/Correspondence to: Walter Eler do Couto. E-mail: waltercouto@usp.br.
}

Recebido em/Received: 15/08/2020; Aprovado em/Approved: 05/12/2020.

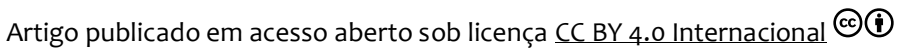


Um dos principais desafios da biblioteca contemporânea é a manutenção de sua relevância social diante de um mundo altamente tecnológico, frequentemente definido como uma sociedade da informação. Assim como ocorreu com o jornalismo, não foram poucos os que declararam a morte da biblioteca em decorrência do surgimento da internet. Mas, também como aconteceu com o jornalismo, esta sentença de morte só se concretiza caso a biblioteca seja impedida de se modernizar.

A biblioteca, muito além de ser um ambiente físico que recebe e acolhe cidadãos, é uma instituição complexa, uma ferramenta epistemológica e cultural, que já se adaptou a outras grandes revoluções midiáticas, como por exemplo o surgimento da imprensa. Hoje, a biblioteca contemporânea é um centro de informação e referência, que atua no mundo e no tempo em que vive. $\mathrm{E}$, diante de um cenário de desinformação generalizada, as bibliotecas se tornam cada vez mais necessárias, porque são confiáveis, metódicas, científicas, e com função social bem definida. É um dos poucos equipamentos culturais que está ramificado e disperso geograficamente de maneira bastante imbricada em todas as camadas sociais, oferecendo indispensáveis serviços e produtos, comprometida na garantia do direito humano e universal de acesso ao conhecimento.

No entanto, depois de quase 30 anos de abertura comercial da internet, muitas bibliotecas não conseguiram se apropriar dos benefícios da tecnologia para sua completa modernização; principalmente no que se refere à digitalização e acesso remoto ao acervo físico. Embora existam barreiras técnicas e financeiras para isso, o principal empecilho está sendo, pelo menos no Brasil, a falta de políticas públicas relacionadas à harmonização dos direitos autorais aos direitos culturais.

Essa situação impacta todas as atividades bibliotecárias ligadas aos serviços e produtos destinados a fomentar o acesso à informação; o que cria uma dificuldade constante no exercício normal dessas atividades, prejudicando o seu funcionamento nos vários tipos de bibliotecas que atuam no Brasil, como as acadêmicas, escolares, públicas ou especializadas.

Não obstante aquelas dificuldades cotidianas, essa situação ganha dimensões extremas frente à pandemia da COVID-19, quando o isolamento social se tornou a única arma possível de sobrevivência, e as atividades ligadas ao ensino, à pesquisa e à cultura passaram a ser realizadas remotamente. Com mais de 1 bilhão de alunos no mundo todo tendo de estudar de casa, com escolas e bibliotecas fechadas, o trabalho dos professores e dos profissionais da informação passou a depender muito das tecnologias digitais.

Neste momento, as bibliotecas contemporâneas tiveram que se reinventar, buscando novas maneiras para dar continuidade ao exercício de suas atividades. As estratégias adotadas para isso variaram muito de biblioteca para biblioteca e de região para região. Variaram de biblioteca para biblioteca, porque, obviamente, elas possuem capacidades tecnológicas distintas; e, variaram de região para região, porque as políticas públicas de acesso à cultura e informação e as legislações de direito de autor oferecem possibilidades muito desiguais na comparação global.

No Brasil, que possui uma legislação bastante restritiva, um dos pontos importantes resultantes desta pandemia é que universidades, docentes, discentes, além dos próprios profissionais da informação, passaram a se questionar sobre as barreiras representadas pelos direitos autorais no ensino e na pesquisa.

Foi nesse contexto que surgiu nosso interesse de refletir sobre a questão já antiga, mas agora intensificada, do acesso à cultura e à informação no Brasil. Com essa finalidade, buscamos identificar iniciativas de bibliotecas em distintos países, portanto, com 
legislação e políticas públicas distintas. Dentre as iniciativas com as quais nos deparamos, identificamos uma proposta surgida no âmago de uma rede de bibliotecas acadêmicas americanas, que acaba por propor um novo e interessante conceito intitulado Controlled Digital Lending ( $C D L)$, ou, em tradução livre, Empréstimo Digital Controlado (EDC).

Identificamos que, independentemente do fundamento jurídico, a ideia central contida no conceito do Empréstimo Digital Controlado é bastante simples e, por isso, talvez possa ser utilizada em outros sistemas legais. A partir desse momento, definiu-se nosso objetivo, qual seja, explorar o conceito do CDL conforme foi desenvolvido nos EUA, depois avaliar brevemente a sua aplicabilidade em um segundo contexto (e, nesse particular, optamos pelo caso francês, porque representa uma situação aparentemente oposta à americana, mas também distante da realidade brasileira), para finalmente avaliar se esta modalidade de empréstimo seria possível no Brasil.

\section{O CONCEITO DE EMPRÉSTIMO DIGITAL CONTROLADO (CDL)}

O Empréstimo Digital Controlado, proposto pelas bibliotecas americanas ${ }^{1}$, é uma modalidade de empréstimo bibliotecário que reproduz no ambiente digital todas as restrições que o empréstimo tradicional dos exemplares teria, causando um impacto idêntico em termos de mercado, mas ampliando e facilitando a atuação da biblioteca no ambiente digital.

Basicamente, ao invés de emprestar o livro físico, a biblioteca concede o acesso a esse exemplar de maneira digital, mas fazendo uso de algumas técnicas que controlam a forma como o usuário poderá utilizar a obra. A ideia central é que a biblioteca possa virtualizar o empréstimo dos livros físicos, reproduzindo no ambiente digital a sua capacidade de acesso físico, mas não a amplificando em número de acessos simultâneos. Assim, se a biblioteca tiver em seu acervo dois exemplares de um livro específico, normalmente ela só poderia realizar dois empréstimos por vez, já que o empréstimo é limitado ao número de exemplares disponíveis. Ao virtualizar esse mecanismo de empréstimo para o Empréstimo Digital Controlado, a biblioteca passaria a reproduzir essa condição no ambiente digital, podendo, então, conceder acesso simultâneo para apenas duas pessoas de cada vez. Se mais pessoas quiserem acessar a mesma obra, precisarão entrar em uma fila, como fariam normalmente com o exemplar físico, por meio de reservas na biblioteca. Ao mesmo tempo, o canal de disponibilização da obra no formato digital não poderia ser qualquer um, já que a biblioteca teria que utilizar tecnologias de DRM (Digital Rights Management) para impedir que a obra fosse reproduzida pelo usuário durante o período de uso.

Portanto, o Empréstimo Digital Controlado é uma reprodução, em ambiente digital, do empréstimo tradicional dos exemplares. Nesse caso, a noção mais importante do conceito de Empréstimo Digital Controlado é a parte do "controlado", porque, pelo controle tecnológico estabelecido pela biblioteca, o usuário não poderá fazer nada além do que poderia fazer se tivesse consultado ou emprestado o exemplar físico na biblioteca. Essa similaridade é importante, porque significa que, se o empréstimo tradicional passa ileso pela regra dos três passos da Convenção de Berna, então o Empréstimo Digital Controlado também deverá passar. Em outras palavras, o Empréstimo Digital Controlado e o empréstimo tradicional do exemplar são

\footnotetext{
${ }^{1}$ Informações adicionais sobre a história desse conceito e sua aplicação nos EUA podem ser consultadas aqui: https://controlleddigitallending.org/ Acesso em 14 de agosto de 2020.
} 
perfeitamente equivalentes e análogos em relação ao impacto causado aos titulares. Já do ponto de vista dos usuários e dos centros de informação, representa um avanço importante, porque facilita a atuação da biblioteca na internet, garantindo a sua modernização.

A fundamentação jurídica do CDL foi desenvolvida por diversos autores, tais como Michelle M. Wu (2016, 2017, 2019a, 2019b), David R. Hansen e Kyle K. Courtney (2018) e Ariel Katz (2016) e consiste, basicamente, na adaptação de duas doutrinas bastante conhecidas: a doutrina do fair use e a doutrina da exaustão dos direitos autorais. Comecemos pela última.

Doutrina da Exaustão de Direitos: essa doutrina, também conhecida como "doutrina da primeira venda" (first-sale doctrine), é a base legal dos empréstimos tradicionais realizados por qualquer biblioteca nos EUA. Essa doutrina diz que, após a primeira venda de um exemplar específico, o autor perde os direitos autorais de distribuição sobre aquele exemplar específico, porque ocorre o esgotamento desse direito. Assim, se alguém compra o exemplar de um livro, o autor daquele livro não pode, pela exaustão do direito de distribuição, impedir que ele seja emprestado, vendido ou alugado pelo dono do exemplar específico. Com base nessa doutrina, as bibliotecas podem comprar exemplares de livros e realizar o empréstimo deles.

No entanto, esse conceito de exaustão de direitos tradicionalmente se aplica apenas ao direito de distribuição dos exemplares e não ao direito de comunicação ao público. É para contornar esse problema que os proponentes do conceito de Empréstimo Digital buscaram garantir a equivalência dessa modalidade ao empréstimo tradicional, colocando muito foco no controle. Desse modo, o Empréstimo Digital Controlado é empréstimo virtualizado, e não comunicação ao público². Por se basear parcialmente na Doutrina da Exaustão dos Direitos Autorais é que os proponentes desse conceito indicam que apenas as obras que foram legitimamente adquiridas pela biblioteca podem se enquadrar no conceito, ficando excluídas do conceito todas as obras que são licenciadas e que não possuem exemplares físicos. Em resumo, o conceito utiliza a exaustão dos direitos de distribuição para decidir a melhor maneira de realizar o empréstimo dos exemplares que pertencem à biblioteca.

Doutrina do Fair Use: o fair use (uso justo ou uso legítimo) é a cláusula de limitação aos direitos autorais nos EUA. Diferentemente do caso brasileiro, que possui um rol${ }^{3}$ exemplificativo de casos especiais considerados de uso livre, a lei dos EUA trabalha com uma cláusula genérica, que, ao invés de apresentar os casos concretos em que o uso é livre, apresenta apenas critérios gerais para aplicação a esses casos concretos. Desse modo, um juiz precisa avaliar, com base nesses critérios, se o uso foi ou não legítimo. Em geral, usos que trazem amplo benefício social, como uso educacional, científico ou cultural, são considerados usos livres protegidos pelo fair use, mas é

\footnotetext{
${ }^{2}$ Recentemente, no caso Capitol Records, LLC v. ReDigi Inc., foi reafirmado, nos EUA, a impossibilidade de exaustão de direitos no que se refere à comunicação ao público pela internet. Todavia, uma especialista afirmou que o ReDigi não aplica o conceito do Empréstimo Digital Controlado, sendo substancialmente diferente dele; portanto, o conceito permanece sem jurisprudência definida: "Embora não se saiba quais fatores adicionais um tribunal pode aplicar ao CDL, ao olhar para os quatro fatores conhecidos, o CDL é tão substancialmente diferente do ReDigi que as conclusões do tribunal do ReDigi não devem ser aplicadas." (WU, 2019a, s/p, tradução nossa). Nesse caso, a principal diferença seria que o ReDigi aplica o conceito de exaustão em obras que originalmente não possuem exemplares físicos (como jogos, softwares ou músicas digitais), enquanto o CDL aplica a doutrina da exaustão exclusivamente em obras que possuem exemplares físicos.

${ }^{3}$ Em Direito, rol significa uma lista de casos ou situações; essa lista pode ser restritiva (quando apenas o que está listado é considerado, praticamente de maneira literal) ou exemplificativa (quando os casos no rol são apenas exemplos que dão direcionamento para a interpretação e aplicação).
} 
preciso avaliar cada caso e analisar sua adequação aos critérios gerais mencionados. Tais critérios são os seguintes:

a) a finalidade e o caráter do uso, incluindo se esse uso é de natureza comercial ou para fins educacionais sem fins lucrativos;

b) a natureza da obra protegida por direitos autorais;

c) a quantidade e a substancialidade da parte usada em relação à obra protegida por direitos autorais como um todo; e

d) o efeito do uso sobre o mercado potencial ou o valor da obra protegida por direitos autorais 4 .

Os proponentes do CDL afirmam que, dada a relevância social do trabalho desempenhado pela biblioteca e dada a ênfase no controle que este conceito possui, ele está perfeitamente adequado aos critérios do fair use. Essas questões legais e formais foram descritas na Declaração de posição sobre empréstimos digitais controlados ${ }^{5}$ e, também, teorizadas em detalhe por David R. Hansen e Kyle K. Courtney:

Basicamente, o CDL [Empréstimo Digital Controlado] trata de replicar com o empréstimo digital os aspectos jurídicos e economicamente significativos do empréstimo físico. Para fazer isso, nós, bibliotecas, devemos realmente exercer o controle do processo. A Declaração identifica seis requisitos específicos para isso. Ela afirma que, para CDL, as bibliotecas devem:

1. garantir que as obras originais sejam adquiridas legalmente;

2. aplicar o CDL apenas a obras de sua propriedade e não licenciadas; 3. limitar o número total de cópias em qualquer formato em circulação a qualquer momento para o número de cópias físicas que a biblioteca possui legalmente (manter uma proporção "propriedade para empréstimo");

4. emprestar cada versão digital apenas para um único usuário por vez, da mesma forma que uma cópia física seria emprestada;

5. limitar o período de tempo para cada empréstimo, de maneira análoga ao empréstimo físico; e

6. usar DRM para evitar a cópia e a redistribuição no atacado. (HANSEN; COURTNEY, 2018, p.03, tradução nossa).

A aplicação mais famosa do CDL é a Open Library do Internet Archive, que disponibiliza grande quantidade de livros seguindo exatamente os critérios acima mencionados. Nessa plataforma, o usuário faz um cadastro e solicita o empréstimo da obra que deseja, após consultar um catálogo. Se a quantidade máxima de empréstimos simultâneos for alcançada (quantidade esta que se relaciona ao número de exemplares físicos que a Open Library possui), o usuário precisa entrar em uma fila de espera para acessar o documento. As obras disponibilizadas por eles a partir do $\mathrm{CDL}^{6}$ não permitem o download, a impressão ou qualquer outra forma de reprodução. Terminado o prazo do empréstimo, o usuário perde o acesso à obra e, se quiser continuar utilizando-a, precisa solicitar um novo empréstimo. Enquanto manteve o foco no controle,

\footnotetext{
4 O fair use está previsto na seção 107 do Copyright law americano, podendo ser consultado aqui: https://www.law.cornell.edu/uscode/text/17/107 Acesso em: 14 de agosto de 2020.

${ }^{5}$ Esta é uma aplicação teórica e doutrinária do fair use que ainda não foi testada judicialmente; para saber quais argumentos eles utilizam para cada um dos critérios, consultar a Position Statement on Controlled Digital Lending, aqui: https://controlleddigitallending.org/statement Acesso em: 14 de agosto de 2020.

${ }^{6}$ A Open Library também disponibiliza obras em domínio público ou obras com licenças públicas; nestes casos específicos, o download é possível, já que a obra não é protegida por direitos autorais.
} 
conforme previa o conceito, a Open Library não foi acionada judicialmente (embora alguns setores tenham criticado retoricamente a iniciativa).

No início da pandemia de COVID-19, o Internet Archive decidiu criar outra biblioteca digital, chamada por eles de The National Emergency Library, que, com base na situação sem precedentes que vivemos, relaxou a ênfase tradicional no controle, passando a permitir que o acesso simultâneo às obras não mais se limitasse ao número de exemplares físicos que eles possuíam.

Rapidamente, os setores representativos dos autores e das editoras, nos EUA, entraram com uma ação judicial com possibilidades milionárias. Por conta disso, o Internet Archive, após cerca de 4 meses de atividades (março a julho de 2020), decidiu interromper o serviço da The National Emergency Library, mantendo apenas o serviço mais tradicional da Open Library, que continua com o foco no controle da quantidade do uso. Ainda não é possível saber o resultado desse processo judicial, mas aparentemente o seu objeto de controvérsia não é o Empréstimo Digital Controlado stricto sensu, mas sim a sua versão emergencial mais flexível.

\section{BREVE RELATO SOBRE EXEMPLO FRANCÊS}

O exemplo do empréstimo de livros no direito francês é bastante interessante para nosso estudo, porque possivelmente representa uma situação oposta ao que acabamos de ver no caso americano. Para começar, os franceses não têm uma concepção tão ampla de exaustão de direitos autorais após a primeira venda. $\mathrm{Na}$ verdade, eles possuem o contrário disso, que é o direito de destinação ${ }^{7}$ e um subtipo dele, mas mais especializado, chamado de direito de empréstimo.

Segundo Frédéric Pollaud-Dulian (2005), o direito de destinação é uma concepção sintética ou amplificada do direito de reprodução, que se amplia no direito francês, conseguindo incidir sobre os usos que se faz da obra e de seu corpo mecânico após a venda do exemplar. Assim, na França, os autores poderiam decidir qual é a destinação de sua obra mesmo após ela ser vendida no formato de exemplar. Pollaud-Dulian considera que, além da amplificação do direito de reprodução, o direito de destinação se ampara na regra de interpretação restritiva dos negócios jurídicos em direitos autorais: portanto, teoricamente, se o autor não autorizou empréstimos, venda ou aluguel de sua obra, então essas ações não estariam permitidas. Vivant e Bruguière (2013), por sua vez, entendem que esse direito possui uma base legal muito frágil, e que é apenas deduzido do texto legal. Por isso, o direito de destinação seria melhor entendido como uma doutrina da destinação, ainda que fartamente comentada e aplicada na jurisprudência. Não é difícil perceber que a doutrina do direito de destinação é como que o oposto da doutrina da exaustão, mas é esta que representa uma tendência modernizadora, mesmo na Europa, e não aquela: "Acima de tudo, devese notar que hoje esse direito de destinação parece um pouco contra a corrente; na Europa e, pela força das circunstâncias, na França, sopra um vento contrário: o de um direito de distribuição sujeito à exaustão." (VIVANT; BRUGUIÈRE, 2013, p.423, tradução nossa). Corrobora essa observação o fato de muitos doutrinadores franceses lembrarem que o direito de destinação é incomum fora da França e da Bélgica.

O caso do direito de empréstimo é um pouco diferente, porque, embora muito relacionado com o direito de destinação na França, ele possui em sua origem uma

7 Uma boa discussão sobre esse tema foi desenvolvida por Séverine Dusollier, aqui: http://www.crid.be/pdf/public/6702.pdf Acesso em 14 de agosto de 2020. 
diretiva europeia e está bem mais positivado no texto legal; ele se originou na Diretiva Europeia 92/100/CEE de 19 de Novembro de 1992, que é "relativa ao direito de aluguer, ao direito de comodato e a certos direitos conexos aos direitos de autor em matéria de propriedade intelectual". O direito de empréstimo estabelecido na França é específico para regular o empréstimo de livros por bibliotecas e foi adicionado ao CPI francês em 2003, no Artigo L133-1, que estabeleceu um sistema de arrecadação e gestão coletiva (similar ao ECAD no Brasil). Assim, os autores possuem o direito de receber royalties pelo empréstimo de livros realizados por bibliotecas públicas francesas, embora não possam se opor a esse empréstimo, transformando o direito em uma espécie de "licença legal paga", e convertendo o direito de destinação em um direito de remuneração (POLLAUD-DULIAN, 2005).

Como o conceito de Empréstimo Digital Controlado parece depender substancialmente da capacidade da biblioteca realizar empréstimos por meio da exaustão dos direitos autorais, pode ser que a sua aplicação fique prejudicada na França, a não ser que possa se justificar por meio de um direito fundamental constitucionalmente estabelecido ou pela reforma legal, já que o direito de empréstimo e o direito de destinação parecem estar com os dias contados do ponto de vista da tendência europeia e mundial.

Não obstante todas essas questões regionais, os franceses não se furtaram ao debate sobre bibliotecas digitais e acesso ao conhecimento. Na verdade, a França tem um dos exemplos mais louváveis do mundo em termos de digitalização de acervos, que é a Gallica, a biblioteca digital da Biblioteca Nacional da França. No entanto, como em outras partes do mundo, os esforços da Gallica acabam se concentrando nas obras já em domínio público (embora a Gallica 2 se esforce para ampliar esses limites). Em 2005, um importante relatório elaborado por François Stasse ${ }^{8}$ debateu as formas como as bibliotecas digitais poderiam atuar com obras ainda protegidas, focando sua atuação no que chamou de "zona cinzenta", que são as obras que não estão mais disponíveis comercialmente, mas que ainda são protegidas legalmente. Stasse propôs que as bibliotecas tivessem a liberdade de realizar a digitalização e as disponibilizações dessas obras; porém, como relata Lionel Maurel (2008), mesmo a ideia sendo juridicamente interessante, ela acabou não se tornando uma política pública porque não teve apoio das editoras e, paradoxalmente, nem dos bibliotecários.

Do ponto de vista constitucional, na França, há apenas uma breve menção aos direitos culturais no Preâmbulo da Constituição de 1946, que faz parte do bloco de constitucionalidade9 . Para Xavier Greffe e Sylvie Pflieger (2015), diferentemente de outras constituições, a Constituição francesa não distribuiu bem as competências em matéria cultural, e os "[...] princípios constitucionais relativos aos objetivos possíveis da política cultural são muito mais vagos." (GREFFE; PFLIEGER, 2015, p.25, tradução nossa).

Por esse motivo, Lionel Maurel (2008) considera arriscada a aplicação direta da Constituição aos direitos culturais das bibliotecas, o que nos faz crer que a aplicação do Empréstimo Digital Controlado por vias constitucionais seja mais difícil por lá do que

\footnotetext{
8 O relatório de Stasse está disponível aqui: https://www.vie-publique.fr/rapport/27770-rapport-au-ministre-de-laculture-et-de-la-communication-sur-lacces-aux Acesso em: 14 de agosto de 2020.

9 Segundo Favoreu et al (2019), o "bloco de constitucionalidade" contém todos os textos legais que possuem força constitucional na França; além da constituição stricto sensu (que é a Constituição da Quinta República Francesa de 1958), o bloco de constitucionalidade inclui o Preâmbulo da Constituição de 1946 (que trata sobretudo de direitos fundamentais e direitos sociais), a Declaração dos Direitos do Homem e do Cidadão de 1789 e a Carta Ambiental de 2004.
} 
por aqui. Como veremos a seguir, essa situação é bem diferente no Brasil, onde os direitos culturais são plenamente estabelecidos na Constituição e bastante comentados em termos de limitação extrínseca. De todo modo, a precaução do teórico francês é importante para lembrar da necessidade de políticas públicas claras que não dependam apenas da interpretação alheia, ainda que essa relutância não se aplique bem ao caso concreto do Brasil:

\begin{abstract}
[...] embora seja fácil pensar nas coisas em termos de um equilíbrio de princípios, é muito mais difícil fazê-lo na prática. Com efeito, os direitos de autor são protegidos de uma forma muito poderosa por um regime jurídico muito preciso que permite apoiar as reivindicações dos detentores de direitos perante os tribunais. Esse ainda não é o caso do direito à cultura, cujos contornos são muito vagos para servir diretamente de base a reivindicações judiciais. Somos, portanto, forçados a contar com exceções legislativas aos direitos autorais, que refletem apenas uma concepção minimalista do direito de acesso à cultura. (MAUREL, 2008, p. 250/251, tradução nossa).
\end{abstract}

\title{
O EMPRÉSTIMO DIGITAL CONTROLADO NO BRASIL
}

A possibilidade ou a impossibilidade de aplicação do Empréstimo Digital Controlado no Brasil é menos clara que nos exemplos vistos até aqui, porque a legislação brasileira é bastante peculiar em seu tratamento às bibliotecas. Peculiar, porque em termos de direitos autorais o legislador escolheu fingir que elas simplesmente não existem. Há um verdadeiro limbo jurídico quando o assunto é a relação entre as bibliotecas e os direitos autorais no Brasil. Para começar, inexiste em nossa legislação uma doutrina da exaustão de direitos autorais; porém, também não há nada parecido ao Direito de Empréstimo/Destinação, conforme vimos no caso francês. O resultado é que até mesmo a mais básica e elementar ação de uma biblioteca, que é o empréstimo de livros para os usuários, não é regulada legalmente no país, nem de maneira positiva, nem de maneira negativa.

A nossa Lei de Direitos Autorais (LDA), a Lei $n^{\circ}$ 9.610/1998, não cita, em nenhum momento, a exaustão dos direitos autorais e nem especifica a legalidade ou a proibição do empréstimo (por bibliotecas ou por usuários em geral) ou da venda de livros usados (como em sebos ou em sites da internet). A única menção ao conceito de exaustão de direitos se refere aos softwares, em sua lei especial ${ }^{10}$, que diz que a exaustão de direitos não é aplicável ao seu aluguel comercial (isso, porém, se refere apenas ao caso dos softwares).

Do ponto de vista teórico, as categorias de corpus mechanicum e de corpus mysticum podem interferir na apreciação desse tema. Essas categorias não estão na lei em si, mas fazem parte da doutrina, ou seja, dão lastro teórico para toda interpretação da lei. Quando a biblioteca adquire o corpus mechanicum, que é o exemplar da obra, não adquire qualquer direito sobre o corpus mysticum, que é a verdadeira obra do espírito protegida por direitos autorais. Nesse caso, se o direito de reprodução for entendido de maneira amplificada, ao adquirir um exemplar o comprador não adquire

\footnotetext{
${ }^{10}$ Trata-se da Lei $\mathrm{N}^{\circ} 9.609 / 1998$, específica para os softwares, que no Art. $2^{\circ}, \S 5^{\circ}$, diz: "Inclui-se dentre os direitos assegurados por esta Lei e pela legislação de direitos autorais e conexos vigentes no País aquele direito exclusivo de autorizar ou proibir o aluguel comercial, não sendo esse direito exaurível pela venda, licença ou outra forma de transferência da cópia do programa."
} 
conjuntamente o direito de distribuir esse exemplar. Mas essa possibilidade soa estranha, porque essas mesmas categorias também podem justificar a impossibilidade de uma amplificação dessa natureza. Como o direito de autor incide apenas sobre o corpus mysticum (obra do espírito), nada desse direito pode controlar o corpus mechanicum (exemplar) que, após ser vendido, pertence ao comprador ${ }^{11}$.

A única exceção prevista em nossa legislação é em relação às obras de arte que ocorrem em exemplares únicos (como esculturas ou pinturas), ou aos manuscritos originais, porque, nesse caso, a LDA estabelece no Art. 38 o chamado "direito de sequência". Como uma escultura geralmente não possui "exemplares", já que o corpus mechanicum e o corpus mysticum ocorrem simultaneamente em um mesmo e único corpus, a legislação concede aos autores o direito de obter uma porcentagem no lucro decorrente da venda desse exemplar único por terceiros. No entanto, a diferença entre corpo mecânico e corpo místico continua a existir, mesmo quando ocorrem simultaneamente em um mesmo corpus; sem mencionar o fato de que o comprador de uma pintura possui o direito emprestá-la livremente para terceiros, sem necessidade de autorização ou pagamento.

Provavelmente, a doutrina da exaustão é pressuposta como certa em nosso sistema por conta de direitos constitucionais; ou, pelo menos, a sociedade age como se ela de fato existisse, como um costume aceito. Do contrário, o empréstimo bibliotecário e a venda de livros usados seriam considerados práticas ilegais no Brasil, o que não se constata. Esse raciocínio deriva do fato de que a LDA também não autoriza expressamente outras atividades inerentes à biblioteca, como a reprodução para conservação, mas, ainda assim, se considera que essas atividades sejam lícitas.

Desse modo, assim como não previu uma doutrina da exaustão, o legislador também se omitiu em relação a outras limitações importantes para as bibliotecas. Em nosso rol de limitações, não há qualquer menção à atividade necessária à conservação dos exemplares, que requer a reprodução integral das obras. No entanto, mesmo assim, a doutrina dominante no Brasil considera que as bibliotecas podem agir livremente nesse sentido (por exemplo, com a digitalização para fins de preservação), por conta da função social da propriedade e dos direitos culturais e informacionais ${ }^{12}$. Para atender a sua função social, os direitos autorais precisam ser flexibilizados, seja por meio da interpretação extensiva das limitações intrínsecas, seja por meio da incidência de limitações extrínsecas.

O Direito de Autor tem como função social a promoção do desenvolvimento econômico, cultural e tecnológico, mediante a concessão de um exclusivo para a utilização e exploração de determinadas obras intelectuais por um certo prazo, findo o qual, a

\footnotetext{
${ }^{11}$ Na clássica abordagem de Fichte (1995), que em 1791 originou essa distinção na teoria jurídica, isso fica bastante claro: "Podemos distinguir dois aspectos de um livro: seu aspecto corporal, o papel impresso, e seu aspecto espiritual. A propriedade do primeiro passa indiscutivelmente para o comprador na compra do livro. Ele pode ler e emprestar quantas vezes quiser; ele pode revendê-lo a quem quiser, e por tanto dinheiro ou tão pouco quanto ele quiser ou puder obter; ele pode rasgá-lo em pedaços ou queimá-lo - e quem poderia brigar com ele?” (FICHTE, 1995, p.142, tradução nossa).

${ }^{12}$ É nesse sentido que orienta o Manual de Direito Autoral para Museus, Arquivos e Bibliotecas, publicado em 2017 pela FGV: “[...] seria absurdo admitir, diante de todos os dispositivos de proteção a patrimônio, cultura e acesso à cultura e à educação previstos na Constituição, que uma cópia com essa finalidade [de preservação] esteja proibida. Trata-se de um caso em que, seja do ponto de vista da interpretação sistemática do ordenamento jurídico brasileiro, seja seguindo pela via de uma função social do direito de autor, a ação pode ser considerada permitida." (VALENTE; FREITAS, p.56, 2017, grifos delas).
} 
obra cai em domínio público e pode ser utilizada livremente por qualquer pessoa. (CARBONI, p.98, 2006).

Nesse contexto, pode ser interessante refletir sobre a própria função social da biblioteca, que é ligada à conservação e à promoção do acesso aos bens culturais.

A biblioteca tem por função a guarda, a organização, e a conservação de acervos, com o objetivo duplo de preservar a memória cultural para as gerações futuras e garantir, para o seu público de usuários imediato, o acesso universal ao conhecimento e às informações que os acervos veiculam. Em última instância, a biblioteca, enquanto ferramenta cultural por excelência, tem por função social estimular a cultura por meio do acesso aos próprios bens culturais. O acesso é promovido tanto pela organização do conhecimento, que garante a recuperação da informação, quanto pela disponibilização das obras para consulta e para empréstimo. A conservação garante $o$ acesso futuro e a recuperação da memória coletiva. Enquanto centro de informação e referência, as bibliotecas desempenham papel indispensável na sociedade contemporânea, marcada pela desinformação. Ao organizar e disponibilizar o conhecimento do passado e do presente, atua como fonte segura de pesquisa e instrução. Por isso, não é legítimo ser sonegado o direito de a biblioteca evoluir tecnologicamente, integrando o antigo ao novo, o impresso e o digital, ainda mais se a justificativa para tal empecilho for um direito de propriedade intelectual - o que se constata tanto pela implicação ética, quanto pela implicação constitucional'13.

Desse modo, parece evidente que a função social do direito autoral é coincidente com a função social da biblioteca, porque ambos foram criados para promover ativamente o desenvolvimento da cultura e do conhecimento na sociedade. Dessa similaridade de função social resulta uma constatação incontornável: sempre que o direito autoral impedir as atividades da biblioteca conforme a função social dela, estará, consequentemente, deixando de cumprir a sua própria função social, o que torna essa situação inconstitucional ${ }^{14}$.

A diferença fundamental não está, portanto, na função social (ambos desejam promover a cultura), mas, sim, nos meios empregados para esse fim. O direito autoral promove a cultura por meio de um exclusivo dado ao autor, o que o estimula a investir tempo e dinheiro na criação de novos bens culturais; a biblioteca, por sua vez, promove a cultura garantindo o acesso amplo aos bens culturais já existentes, inclusive o acesso que os autores eventualmente farão para obtenção de fontes na criação de suas próprias obras.

À primeira vista, os meios empregados para atingir um mesmo fim são terrivelmente conflitantes e correm o risco de autoexclusão. No entanto, a situação concreta de interação entre os dois deve ser de harmonia, pela busca do objetivo comum, e não a suplantação de um pelo outro. Assim, está claro que a biblioteca não pode ignorar a existência dos direitos autorais e, ao contrário, deve observá-los ativamente. Por conta disso, tal modalidade de empréstimo digital precisa ser "controlada", do contrário iria atrapalhar a exploração normal da obra. Ao mesmo tempo, os titulares não podem abusar de seu direito de exclusivo, como algumas vezes fazem, criando uma cultura do “nada pode sem eu deixar”. Ninguém irá duvidar dessa necessidade de harmonização,

\footnotetext{
${ }^{13}$ A Função Social da Propriedade é estabelecida no Art. $5^{\circ}$, inc. XXIII, da Constituição Federal.

14 "O direito autoral desempenha assim necessariamente uma função social, como qualquer outro direito. Por isso, se a disciplina autoral desconhecer a função social do direito, é inconstitucional” (ASCENSÃO, 2008, p.321).
} 
porém a sua concretização é historicamente um ponto de disputa e controvérsia, dadas as múltiplas amplitudes possíveis.

\section{LIMITES INTRÍNSECOS E EXTRÍNSECOS ADEQUADOS À FUNÇÃO SOCIAL DO DIREITO AUTORAL NO BRASIL}

Muitos teóricos do direito autoral sustentam que existem dois tipos de limitações aos direitos autorais, as limitações intrínsecas, que fazem parte da própria LDA nos Artigos 46, 47 e 48; e as limitações extrínsecas, que resultam do relacionamento da LDA com outras leis e com a Constituição Federal. Além disso, um número cada vez maior de intérpretes considera que o rol das limitações é meramente exemplificativo, caracterizando-se como um direito dos usuários, o que permite a sua interpretação extensiva e a analogia, ampliando as possibilidades de usos livres.

Conforme explica Bruno Lewicki (2007), a norma que obriga a interpretação a ser restritiva em casos de rol taxativo está intimamente relacionada com o entendimento da natureza do rol. É um caso de teoria jurídica complexa, porém muito bem abordada por Lewicki em sua tese: se a lei não define textualmente a natureza de um rol, utilizando expressões que deixam claro a sua natureza taxativa ou exemplificativa, cabe se perguntar sobre o princípio axiológico desse rol e sua função social no momento de o intérprete decidir se é taxativo ou exemplificativo. Se a natureza das limitações for caracterizada como uma lacuna, uma exceção diante de uma regra, então o rol será taxativo. Nesse caso, considera-se que os Direitos Autorais são a norma e as limitações meras exceções à norma. Porém, se a natureza jurídica das limitações não for de caráter excepcional, mas constituírem verdadeiros Direitos dos Usuários, então o seu rol não deve ser entendido como taxativo, mas sim exemplificativo. Como consequências naturais de um rol meramente exemplificativo, conclui Lewicki (2007), ficam permitidas a interpretação extensiva e a analogia.

Dizer que o rol de limitações é apenas exemplificativo significa dizer que outras hipóteses podem ser lá adicionadas, que os exemplos apenas dão uma diretriz na interpretação, que as noções de uso livre e de direito do usuário podem ser aplicadas em casos análogos aos lá exemplificados ou estendidas aos casos que são similares.

Allan de Rocha Souza (2011) vem chamando atenção para o fato de que a jurisprudência brasileira considera a possibilidade de interpretação extensiva das limitações desde os anos de $1980^{15}$, o que é ignorado pelos defensores da interpretação restritiva. Recentemente, Allan Rocha de Souza e Tel Amiel (2020) desenvolveram um guia de direitos autorais para educação aberta e a distância que se baseou em grande medida na interpretação extensiva. Como fundamento, os autores citam a consolidação cada vez maior na jurisprudência de cortes superiores da noção de que as limitações são exemplificativas $^{16}$ e, também, citam a elaboração do Enunciado $115^{17}$ da III Jornada de Direito Comercial do Conselho da Justiça Federal, que orienta os tribunais a adotarem a interpretação extensiva das limitações.

\footnotetext{
$15 \mathrm{O}$ autor cita, por exemplo, que a interpretação extensiva já foi utilizada no Recurso Extraordinário n. 113.505-1 58, julgado em 28 de fevereiro de 1989.

${ }^{16}$ Eles citam o Recurso Especial 964.404/ES de 2011 do Supremo Tribunal de Justiça.

17 “ENUNCIADO 115 - As limitações de direitos autorais estabelecidas nos arts. 46, 47 e 48 da Lei de Direitos Autorais devem ser interpretadas extensivamente, em conformidade com os direitos fundamentais e a função social da propriedade estabelecida no art. $5^{\circ}$, XXIII, da CF/88."
} 
O movimento de compreensão das limitações na figura de direitos dos usuários e não mais na figura de meras exceções ao direito alheio é observado no mundo todo como uma tendência modernizadora (CHAPDELAINE, 2017). Trata-se de uma evolução do pensamento jurídico em matéria de direito autoral, que evita que se trate o usuário como um marginal; evita, também, classificar todos os usuários como "piratas" em potencial ${ }^{18}$.

As disputas em torno da reprodução de obras no interior de bibliotecas exerceram historicamente relevante influência na questão das limitações aos direitos autorais e na ideia de direito dos usuários. Em 2004, por exemplo, a Suprema Corte canadense julgou um caso paradigmático envolvendo uma biblioteca, na ação conhecida como CCH Canadian Ltd. vs. Law Society of Upper Canada. A biblioteca da Law Society realizava digitalizações para a comunidade jurídica canadense, por meio de um serviço chamado de "fotocópia personalizada" e a editora CCH Canadian Ltd. se sentiu prejudicada e entrou com uma ação por violação de direitos autorais. A biblioteca da Law Society alegou que o caso se enquadrava como fair dealing (que é o nome da limitação aos direitos autorais no Canadá) e que, portanto, não se tratava de uma violação. $O$ caso foi parar na Suprema Corte, que não apenas decidiu em favor da biblioteca da Law Society, afirmando se tratar de caso de uso livre, como aproveitou a ocasião para enfrentar a controvérsia a respeito da natureza das limitações, afirmando que estas não eram meras exceções à lei, mas sim um caso de Direito dos Usuários. ${ }^{19}$

Do ponto de vista das limitações extrínsecas, podemos citar como possibilidades de limitações aos direitos autorais o impacto que exerce sobre eles os direitos constitucionais de acesso à informação e à cultura. Esses direitos são consagrados na Constituição Federal em vários lugares, especialmente no Art. $5^{\circ}$, inc. XIV, Art. 215, Art. 216 e Art. 216-A.

Como lembra José de Oliveira Ascenção, “o Direito Autoral é um ramo do Direito como qualquer outro" (2008, p.320), e, por causa disso, é tão submetido à Constituição como qualquer outro, sendo por ela extrinsecamente limitado. Refletindo sobre o caso específico das bibliotecas, esse autor considerou que a Constituição permite a digitalização para fins de preservação com base nos direitos culturais e, além disso, considerou ser possível a disponibilização controlada da obra digitalizada:

Isto implica que, para estes fins, a digitalização seja livre, não dependendo de autorização nem pagamento. A finalidade cultural

\footnotetext{
${ }^{18}$ Sobre esta implicação, observe-se a seguinte citação da teoria jurídica canadense: "O termo "direitos dos usuários" é importante principalmente porque cria o potencial para conflitos entre proprietários e usuários serem travados em pé de igualdade e confere legitimidade às demandas de usuários que normalmente são caracterizados como oportunistas, aproveitadores e canalhas. Os usuários que reivindicam a liberdade de lidar de forma justa com obras protegidas por direitos autorais podem agora ser vistos como exigindo o reconhecimento de seus próprios direitos, e não simplesmente buscando violar ou limitar os direitos de terceiros. Além disso, não é mais defensável equiparar o fair dealing com "roubo justo" [fair stealing]; não é roubar usar algo que temos o direito de usar. A esperança é que o conceito de direitos dos usuários pavimente o caminho para uma abordagem mais equilibrada ao fair dealing, garantindo que o foco não seja apenas nos direitos dos quais o proprietário dos direitos autorais está impedido de desfrutar." (CRAIG, 2005, p. 454, tradução nossa).

${ }^{19}$ Assim decidiu a suprema corte canadense: "Antes de revisar o escopo da exceção de fair dealing sob a Lei de Direitos Autorais, é importante esclarecer algumas considerações gerais sobre as exceções à violação de direitos autorais. Em termos de procedimento, o réu deve provar que lidou com a obra de maneira justa; no entanto, a exceção de fair dealing talvez seja mais apropriadamente entendida como parte integrante da Lei de Direitos Autorais do que simplesmente uma defesa. Qualquer ato que se enquadre na exceção de fair dealing não será uma violação de direitos autorais. A exceção de fair dealing, como outras exceções da Lei de Direitos Autorais, é o direito do usuário. Para manter o equilíbrio adequado entre os direitos do proprietário dos direitos autorais e os interesses dos usuários, ele não deve ser interpretado de forma restritiva" (2004, s/p, tradução nossa). Detalhes sobre o caso podem ser lidos aqui: https://scc-csc.lexum.com/scc-csc/scc-csc/en/item/2125/index.do Acessado em: 14/08/2020.
} 
passa à frente da reserva de exploração e não a atinge, ou só marginalmente a atingirá.

É ainda claro que a obra digitalizada não terá de ser mantida secreta para meras finalidades de conservação. Pode, também livremente, ficar aberta à consulta dos usuários do estabelecimento - biblioteca, arquivo ou museu - como qualquer obra em suporte material. $\mathrm{O}$ autor em nada é prejudicado com isso, pelo que não é legítimo criar impedimentos ao fim cultural. (ASCENÇÃO, 2008, p.346).

Além da possibilidade de digitalização para fins de preservação (e de consulta in loco), Ascenção refletiu sobre a possibilidade de disponibilizar em rede, para os usuários da biblioteca, as obras digitalizadas. Para ele, essa hipótese seria possível se a disponibilização fosse controlada, como na disponibilização via intranet ${ }^{20}$ de acesso restrito de uma ou vária bibliotecas conectadas. Essa hipótese lembra o conceito do Empréstimo Digital Controlado, porque estabelece o princípio do controle como requisito para disponibilização da obra em rede, variando apenas a forma como esse controle é realizado, mas tendo igualmente como fim não atrapalhar a exploração normal da obra. Não atrapalhar a exploração normal da obra é um dos requisitos da regra dos três passos da Convenção de Berna, que precisa ser observada em qualquer hipótese de limitação aos direitos autorais.

De maneira similar, ao refletirem sobre a disponibilização de material para alunos no contexto da educação a distância, Allan Rocha de Souza e Tel Amiel (2020) parecem aplicar um foco parecido à ideia de disponibilização controlada. Nesse caso, segundo eles, os professores podem disponibilizar parte de qualquer obra (capítulos ou artigos), contanto que essa disponibilização ocorra "[...] na medida do necessário, para os alunos regularmente inscritos, preferencialmente por meio dos canais oficiais da instituição" (Rocha de Souza; Amiel, p. 19, 2020). O controle sobre a disponibilização é, portanto, central para evitar que ela atrapalhe a exploração normal da obra. No caso da educação online, o controle sugerido pelos autores é relativo à comunidade destinatária da disponibilização, que é reduzida aos alunos da classe; ao canal da disponibilização, que é o oficial; e à quantidade da disponibilização, que é um pequeno trecho. Eles entendem que as obras integrais também podem ser disponibilizadas, mas com mais prudência, citando o exemplo da interpretação da USP e da UFRJ sobre a reprodução integral de obras estrangeiras ou que estejam fora de catálogo ${ }^{21}$. Ou seja, novamente, o raciocínio é bastante similar ao aplicado ao Empréstimo Digital Controlado, que é a disponibilização mediante controle, diferindo apenas no tipo de controle escolhido.

Sendo assim, em teoria, por conta dos Direitos Culturais e Informacionais, é lícito afirmar que a Constituição Federal de 1988 é inteiramente compatível com o conceito do Empréstimo Digital Controlado. Na aplicação indireta, por meio do estímulo às

\footnotetext{
${ }^{20}$ Diferentemente da Internet, que é de acesso amplo e público, a Intranet é uma rede privada, cujo acesso é mais controlado e mais restrito.

${ }^{21}$ Os exemplos da USP e da UFRJ são muito importantes para a aplicação do CDL no Brasil, porque demonstram que algumas instituições podem, diante da dubiedade da legislação ou da falta de uma jurisprudência clara, escolher a interpretação mais favorável à sua comunidade. No caso da USP, a "RESOLUÇÃO № 5213, DE 02 DE JUNHO DE 2005" instituiu a interpretação extensiva da cópia para uso privado, regulando as fotocópias realizadas nas bibliotecas da universidade. É bem verdade que a USP se baseou na autonomia universitária para realizar essa interpretação, o que pode deixar outros tipos de instituições em desvantagem; todavia, acreditamos que os direitos constitucionais à informação e à cultura já sejam suficientes para embasar uma resolução dessa natureza, independentemente de a instituição em questão ser uma universidade com autonomia ou uma biblioteca pública convencional. A UFRJ seguiu caminho parecido na "RESOLUÇÃO N 19/2010", que se fundamentou, além da autonomia universitária, no direito à informação dos estudantes e professores.
} 
políticas públicas, o Art. 215 e o Art. $216-\mathrm{A}, \$ 1^{\circ}$, inciso II, estabelecem o princípio da universalidade do acesso, favorecendo a inclusão dessa modalidade de empréstimo em qualquer política pública relacionada à cultura. Em outras palavras, se uma política pública positivasse em lei o Empréstimo Digital Controlado como um direito em benefício das bibliotecas, ele seria plenamente constitucional porque estaria relacionado ao princípio da universalidade de acesso.

$\mathrm{Na}$ verdade, a promoção do equilíbrio entre direito autoral e direitos culturais, assim como a ampliação das limitações voltadas para a internet são objetivos declarados pelo Estado brasileiro em seu Plano Nacional de Cultura (PNC) $)^{22}$, mas que ainda não conseguiram se efetivar como uma política pública. Resta saber se a Constituição poderia ser usada para permitir essa modalidade de empréstimo independentemente da existência de uma política pública consolidada, na condição de limite extrínseco ao direito de autor e mediante interpretação sistemática. Esta pergunta é importante, porque, tradicionalmente, os direitos fundamentais e os direitos sociais contidos na Constituição são classificados como "normas programáticas", que funcionam mais como uma aspiração para criação de políticas públicas do que como direitos concretos. No entanto, esse entendimento tem se modificado e a tendência atual é considerar que as normas programáticas são direitos reais aplicáveis aos casos $\operatorname{concretos}^{23}$. Parece ser exatamente esse o entendimento dos autoralistas que consideram os direitos culturais do texto constitucional como limitação extrínseca ao direito autoral:

Em suma, entendemos que, não obstante o fato de o direito de acesso à informação e à cultura (que é um dos direitos que compõe os chamados "direitos culturais") ter sido positivado como norma programática em nossa Constituição Federal e de o direito de autor não estabelecer a possibilidade de sua limitação na forma de um princípio geral em situações em que deva prevalecer, entendemos que esse direito deverá ser invocado em determinadas situações concretas [...], com base no princípio da proporcionalidade, sempre que $o$ interesse público tiver de prevalecer sobre o interesse particular do autor. (CARBONI, 2006, p.210).

Vimos que os doutrinadores brasileiros, de maneira geral, entendem que o empréstimo tradicional dos exemplares e a digitalização para fins de preservação realizada pela biblioteca são modalidades de uso livre permitidas pela interpretação sistemática da Constituição Federal, ainda que não tenham sido claramente citadas no rol das limitações da LDA. Também vimos que o Empréstimo Digital Controlado é uma modalidade de empréstimo bibliotecário equivalente e análoga ao empréstimo

\footnotetext{
22 O PNC cita como objetivos:

“1.9 Fortalecer a gestão pública dos direitos autorais, por meio da expansão e modernização dos órgãos competentes e da promoção do equilíbrio entre o respeito a esses direitos e a ampliação do acesso à cultura. [...] 1.9.4 Adequar a regulação dos direitos autorais, suas limitações e exceções, ao uso das novas tecnologias de informação e comunicação". Disponível em: http://www.planalto.gov.br/ccivil_03/_ato2007-2010/2010/lei//12343.htm Acesso em: 14/08/2020.

${ }^{23}$ No entendimento mais antigo, as normas constitucionais programáticas eram meras promessas de direito, e não direitos reais, e poderiam ser usadas para criação de políticas públicas e leis específicas, mas não se aplicavam diretamente em casos concretos. Segundo Paulo Roberto Lyrio Pimenta (2012), um entendimento doutrinal mais moderno sobre as normas constitucionais programáticas foi referendado pelo STF em 2004, na Arguição de Descumprimento de Preceito Fundamental (ADPF) n45, e em várias decisões posteriores, em que a corte passou a entender que essas normas programáticas possuem eficácia e podem ser aplicadas em casos concretos, já que o texto constitucional não poderia ser lido como mera promessa inconsequente.
} 
tradicional, que apenas utiliza as tecnologias digitais para facilitar e modernizar o seu serviço de empréstimos.

Analisemos, agora, as implicações dessas constatações. Não estamos, aqui, propondo uma interpretação constitucional dos direitos de acesso aos bens culturais, apenas avaliando as implicações lógicas das interpretações já existentes.

Como as situações são semelhantes, ou mesmo equivalentes, não há motivos lógicos para permitir uma e negar a outra, já que a interpretação que permite uma deverá também permitir a outra, pela simples extensão de seus princípios. Ou seja, se o empréstimo tradicional e a digitalização são hipóteses constitucionalmente inferidas de limitação extrínseca ao direito do autor, o mesmo raciocínio deve ser aplicado ao Empréstimo Digital Controlado. Nesse caso, é lícito inferir do texto constitucional o direito de a biblioteca realizar essa modalidade de empréstimo; no entanto, por ser um conceito de empréstimo recentemente desenvolvido, não há jurisprudência sobre o tema nem mesmo nos EUA, onde surgiu.

Obviamente, o oposto também é verdadeiro: se há argumentação jurídica sólida para impedir a existência do Empréstimo Digital Controlado em nosso sistema, então a mesma argumentação deve impedir o empréstimo tradicional e a digitalização realizada na biblioteca. No entanto, essa seria uma situação absurda, porque estaríamos dizendo que a totalidade das bibliotecas brasileiras cometem crimes ou estão "do lado errado da lei”, apenas porque realizam meros empréstimos.

\section{CONCLUSÃO}

Os direitos culturais e informacionais garantem, teoricamente, uma atuação mais ampla das bibliotecas. No entanto, a falta de políticas públicas claras gera um efeito paralisante nos profissionais da informação, que, preocupados com os direitos autorais (e com sua política de pânicos morais), evitam tomar para si alguns riscos.

Esse efeito paralisante é perfeitamente compreensível, porque não cabe ao profissional assumir esses riscos individualmente. As instituições culturais, informacionais e educacionais (bibliotecas, museus, arquivos, universidades, escolas etc.) é que devem, com base nas interpretações disponíveis, criar planos de ação e diretrizes claras, com o objetivo exclusivo de cumprir a sua obrigação na promoção do acesso à cultura e à informação.

\section{REFERÊNCIAS}

ASCENSÃO, José de Oliveira. As "exceções e limites" ao direito de autor e direitos conexos no ambiente digital. Revista da ESMAPE, v. 13, n. 28, p. 315-351, 2008.

CARBONI, Guilherme. Função social do direito de autor. Curitiba: Juruá Editora.

CHAPDELAINE, Pascale. Copyright user rights: contracts and the erosion of property. Oxford: Osford University Press, 2017.

COURTNEY, Kyle; HANSEN, David. A white paper on controlled digital lending of library books. 2018. Disponível em: https://dash.harvard.edu/handle/1/42664235. Acesso em: 15 ago. 2020. 
CRAIG, Carys. The changing face of fair dealing in canadian copyright law: a proposal for legislative reform: in the public interest: the future of canadian copyright law. toronto, on: irwin law, 2005. Disponível em: https://digitalcommons.osgoode.yorku.ca/scholarly_works/76. Acesso em: 12 jul. 2020.

FAVOREU, Louis, et al. Droit constitutionnel. 21. ed. Paris: DALLOZ, 2019.

FICHTE, Johann Gottlieb. Preuve de l'illégitimité de la reproduction des livres, un raisonnement et une parabole. In: KANT, Immanuel. Qu'est-ce qu'un livre?: textes de Kant et de Fichte. Paris: Presses universitaires de France, 1995.

GREFFE, Xavier; PFLIEGER, Sylvie. La politique culturelle en France. 2. ed. Paris: La Documentation française, 2015.

KATZ, Ariel. ID 3024304: copyright, exhaustion, and the role of libraries in the ecosystem of knowledge. SSRN Scholarly Paper. Rochester, NY: Social Science Research Network, 2016. Disponível em: https://papers.ssrn.com/abstract=3024304. Acesso em: 15 ago. 2020.

LEWICKI, Bruno. Limitações aos direitos do autor: releitura na perspectiva do direito civil contemporâneo. 2007. Tese (Doutorado) - Universidade do Estado do Rio de Janeiro, Rio de Janeiro, 2007.

MAUREL, Lionel. Bibliothèques numériques : le défi du droit d'auteur. 2008. Disponível em: https://hal-univ-paris10.archives-ouvertes.fr/hal-01366318. Acesso em: 15 ago. 2020.

PIMENTA, Paulo Roberto Lyrio. As normas constitucionais programáticas e a reserva do possível. Revista de Informação Legislativa, n. 193, p. 14, 2012. Disponível em: https://www2.senado.leg.br/bdsf/bitstream/handle/id/496554/000940642.pdf?seque nce=1\&isAllowed=y. Acesso em: 15 ago. 2020.

POLLAUD-DULIAN, Frédéric. Le droit d'auteur. Paris: Economica, 2005.

SOUZA, Allan Rocha de; AMIEL, Tel. Guia direito autoral e educação aberta e a distância: perguntas e respostas. 2020. Disponível em: https://zenodo.org/record/3964713\#.XzZ3XuhKiUn. Acesso em: 15 ago. 2020.

SOUZA, Allan Rocha de. Direitos autorais e acesso à cultura. Liinc em Revista, v. 7, n. 2, 2011. Disponível em: http://revista.ibict.br/liinc/article/view/3324. Acesso em: 15 ago. 2020.

STASSE, François. Rapport au ministre de la culture et de la communication sur l'accès aux œuvres numériques conservées par les bibliothèques publiques. [S.d.]. Disponível em: https://www.vie-publique.fr/rapport/27770-rapport-au-ministre-de-la-culture-etde-la-communication-sur-lacces-aux. Acesso em: 15 ago. 2020.

VALENTE, Mariana Giorgetti; FREITAS, Bruna Castanheira de. Manual de direito autoral para museus, arquivos e bibliotecas FGV, 2017. Disponível em: http://bibliotecadigital.fgv.br/dspace/handle/10438/19038. Acesso em: 15 ago. 2020. 
VIVANT, Michel.; BRUGUIÈRE, Jean-Michel. Droit d'auteur et droits voisins. 2. ed. Paris: Dalloz, 2013.

WU, Michelle M. Collaborative academic library digital collections Post-Cambridge University Press, HathiTrust and Google Decisions on fair use. Journal of Copyright in Education \& Librarianship, v. 1, n. 1, 2016. Disponível em: https://www.jcelpub.org/article/view/5921. Acesso em: 15 ago. 2020.

WU, Michelle M. ID 2968410: piece by piece review of digitize-and-lend projects through the lens of copyright and fair use. SSRN Scholarly Paper. Rochester, NY: Social Science Research Network, 2017. Disponível em: https://papers.ssrn.com/abstract=2968410. Acesso em: 15 ago. 2020.

WU, Michelle M. Revisiting controlled digital lending post-ReDigi. First Monday $2019 a$. Disponível em: https://firstmonday.org/ojs/index.php/fm/article/view/9644. Acesso em: 15 ago. 2020.

WU, Michelle M. ID 3328624: shared collection development, digitization, and owned digital collections. Rochester, NY: Social Science Research Network, 2019b. Disponível em: https://papers.ssrn.com/abstract=3328624. Acesso em: 15 ago. 2020. 